\title{
Workflow Optimization with Construction Scheduling under a Lean Perspective
}

\author{
Marco A. Bragadin ${ }^{1}$ and Kalle Kahkonen ${ }^{2}$ \\ 1 Alma Mater Studiorum - University of Bologna, Bologna, Italy, marcoalvise.bragadin@unibo.it \\ 2 Tampere University, Tampere, Finland, kalle.kahkonen@tuni.fi
}

\begin{abstract}
Construction scheduling produces the most important construction documents as they disclose the total project duration, project stages and times of work packages, activity costs per time period, logical sequence of activities and corresponding consequences for quality and safety. The production model displayed by the schedule should address Lean principles of production, mainly the reduction of waste created by idle time of crews due to a non-optimized workflow and takt-time planning. In a Lean Construction perspective, the project schedule should address the workflow of activities and of construction crews through the workspaces of the building. Location-Based Management System (LBMS) is a recent and innovative method that aims at planning and managing construction projects in a process-oriented way. This approach is based upon the Location Breakdown Structure (LBS), a hierarchical categorization of the workspaces where construction activities are performed by trades. As different trades need different types of workspaces, the LBS should be trade and time dependent. In an on-going research an improved scheduling method for construction operations has been developed, based on a CPM - Precedence Network plotted on a Resource-Space chart. Space Units of the project work are identified by a Location Breakdown Structure (LBS), and project activities are identified by two dimensions coordinate system based on Resources (i.e. construction crews) and working spaces (e.g. floors of a multi-storey building). Therefore the network model can be structured understanding resource and space constraints. Space Units can be modified in different stages of the execution according to trade - specific requirements, therefore creating a time-dependent LBS, and resource-based activity plotting can enhance workflow modeling through locations. Takt time of workflow in each space unit can be easily detected and optimized through balancing the duration of the sequenced activities of the space unit. The aim of the proposed approach is to increase the quality of the produced schedule by addressing Lean principles concerning work-flow optimization and takt-time detection and planning. The scheduling approach has been tested on a sample project.
\end{abstract}

(C) 2020 The Authors. Published by Budapest University of Technology and Economics \& Diamond Congress Ltd Peer-review under responsibility of the Scientific Committee of the Creative Construction Conference 2020.

Keywords: takt time, construction, lean construction, project schedule, Location Breakdown Structure

\section{Introduction}

Construction projects are very specific industrial projects. One of the most important features of construction production is related to building site, as building construction is an industrial process in which workers build not only the product but also the working location, i.e. the construction site. Therefore, space for construction activities, including materials, machines and fabrication stations, traffic routes and welfare facilities must be designed, organized and planned [1]. Lean production philosophy originated in Japan in the 1950' and its first application was the "Toyota Production System". Lean construction mainly addresses work-flow optimization, quality control, value management and waste elimination [2]. Seeing production as a flow of materials, information, work and products is a main concept of lean philosophy [3]. Ballard and 
Howell [4] proposed a new approach to production management based on production planning and control where main attention is on integrative work structuring by key partners such as designers, contractors and suppliers [5] to adopt lean principles. Recently, takt planning and control has gained a lot of interest and it is seen as a next important development step [6]. The term "takt" means a certain pre-selected regularity with which something gets done; for example one week can define rhythm, according which every line can move in sync with others resulting in a continuous flow process. Takt time planning means defining a pace of production process that best suits clients need [7], [8]. This is another important contribution of the lean approach to project scheduling that has the aim of understanding and designing a better workflow structure within the schedule model. Lean approach to project scheduling focuses on the understanding of the organization of the various materials, trades, and subcontractors in the project processes [8] and of the flows of work, materials, information, products in the project. This can be achieved only by considering the construction workspace. Construction workspace is at the same time one of the main components and constraints of construction scheduling, due to production context and building product characteristics. Also, space requirements can have very important effects on occupational safety and production quality [9], [10]. Workflow and workspaces are generally difficult to proactively plan and manage, because of the dynamic nature of construction production where trades work moving into a site layout that changes continuously as processes progress. Another feature that adds complexity to workflow planning is that trades of different kinds (i.e. civil, mechanical, electrical, etc.) need different patterns of workspace, therefore location modeling should be dependent on time and trades. As standard planning and scheduling of a construction project can be achieved through networking techniques, the workflow and space - related components of the schedule are difficult to model and to consider efficiently, even by an experienced project scheduler. This is because space is not represented in the network model. The objective of the research work behind this paper is to propose a resource and space-oriented scheduling approach that can help project scheduler to understand takt times of the project and to adopt lean principles in construction scheduling.

\section{Point of departure}

Many scheduling methods have been proposed in literature in order to improve construction project workspace management with a scheduling model. As crews perform activities from a space unit of the project to another one, it might be advantageous to arrange for such crews to work continuously, without interruptions, thereby preventing idle intervals of equipment and manpower. Riley and Sanvido [1] observed that current space planning in multi-storey building construction is limited to site layout and logistics, and needs to be improved addressing work sequence. Koskela [2] observed that traditional network planning requires the division of workflow into specific activities thus making more difficult workflow optimization. Kahkonen [11] developed a scheduling model that focuses on the logic of building construction and activity dependencies due to resources and locations. El-Rayes and Mosehli [12] suggested that resource - driven scheduling accounts directly for crew work continuity and facilitate effective resource utilization. Yi, Lee and Choi [13] presented a heuristic method for network construction and development for repetitive-units project, with the aim of minimizing total project duration by reducing idle time of resources and spaces. Ballard [5] proposed the Last Planner System of Production Control composed of two phases, the planning phase and the execution or control phase. In the planning phase customer needs are determined and translated into design criteria, then work structuring is performed. Work structuring is defined as the process of activity identification, sequencing and scheduling. In the execution or control phase work-flow control and unit production control are performed. The seminal work of Akinci et alii [9] investigated the time-space conflicts in construction projects. Six type of spaces required by construction activities were detected. As activities can have time overlaps, time - space conflicts may occur. The basic method suggested by researchers and practitioners for time - space construction project modelling is the linear scheduling method, flow line or linear planning, integrated with a network model. A Location-Based Management System was introduced by Kenley and Seppanen basing on a Location Based Structure (LBS) that creates a work-oriented hierarchical decomposition of project work site locations [14]. Tsao et alii [15] presented a work structuring research methodology. Work structuring in Lean Construction is defined as the development of operation and process design in alignment with product design, structure of supply chains, allocation of resources, and design for assembly efforts [5]. The aim of work structuring 
is making the workflow more reliable and quicker while delivering value to the customer. Frandson et alii [7] and Tommelein [8] highlighted the need of developing not only the overall construction schedule, usually delivered with a CPM - based activity network, but also the schedule for production as an output of production system design, i.e. work structuring. Work structuring can be achieved through takt time planning, meaning the pace of production process that best suits clients need [7], [8]. Tommelein [8] indicates that the design of zones in the workspace to enhance lean workflow with takt time planning needs to take into account different trades, as different trades needs different workspace patterns. Garcia-Lopez et alii [16] presented a work structuring method that allows field managers to explicitly represent construction activities, flows and flow movement through the project, the Activity-Flow Model (AFM). In summary, apparently due to its significance there are continuous interests around construction scheduling amongst academic scholars and industry experts. These efforts have produced interesting results that have also started to address topics and principles of importance within lean construction. The research presented in this paper is providing new insights for this continuum of research and development of methods for construction scheduling. The research presented in the following proposes a method to understand workflow and work-space characteristics of a construction project for takt planning purposes, thus creating a process-oriented environment for construction schedule production, and enabling high quality scheduling.

\section{Proposed approach}

\subsection{REPNET: Repetitive Networking technique}

In an on-going research an improved scheduling method for construction operations has been developed, based on a CPM - based Precedence Network plotted on a Resource-Space chart termed Repetitive Networking Technique (REPNET), integrated with time-space diagrams. Locations or Space Units of the project are identified by a Location Breakdown Structure (LBS) like in the LBM System, and project activities are identified by a two dimensions coordinate system based on Resources (i.e. construction crews) and trade-oriented working Spaces (e.g. floors of a multi-storey building) [17]. The REPNET heuristics provide optimized activity scheduling maintaining the work continuity constraint and the As-Soon-As-Possible total project duration calculation. The proposed method consists of a Precedence Diagram Network of the construction project plotted on a resource - space chart, with the $x$-axis representing resources and the $y$ - axis representing space units of the project. The two coordinates identify each network node representing an activity performed in a specific space unit: the first coordinate is the main resource performing the activity and the second coordinate is the work-space in which the activity is to be performed. Resources in the $\mathrm{x}$-axis of the chart are work crews or equipment that is planned to perform activities. Resources can be grouped by work item i.e. masonry, plastering, floor concrete slab etc. In this way, in every column of the chart repetitive and non-repetitive network activities are grouped by resources (Fig. 1 and 2 (a)).

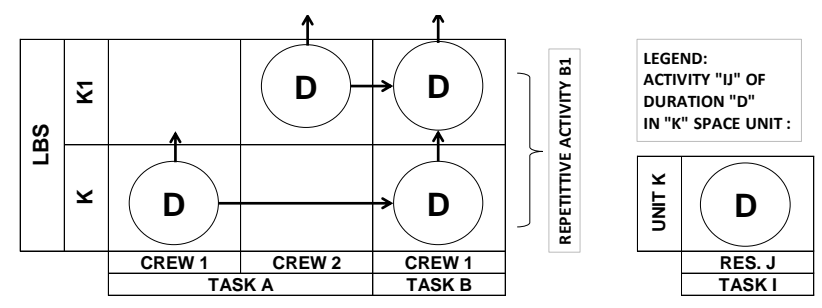

Fig. 1: Network Diagram plotted on a Resource-Space Chart [13], [17].

The LBS indicates the hierarchical decomposition of space units of the project that are plotted on the y-axis. Space units are the locations where only one crew can perform one activity at a time, and in every line of the chart activities are grouped by workspaces. Note that the LBS structure depends on the work decomposition and project phase, meaning the phase in which resources with the same workspace pattern are involved [8]. Therefore, the REPNET chart should be specific for each construction phase (Fig. 2 (a)). The output of the project schedule can be displayed with a time - space diagram where the $\mathrm{x}$-axis represents time and $y$-axis represents the LBS of the project (Fig. 2 (b)). 


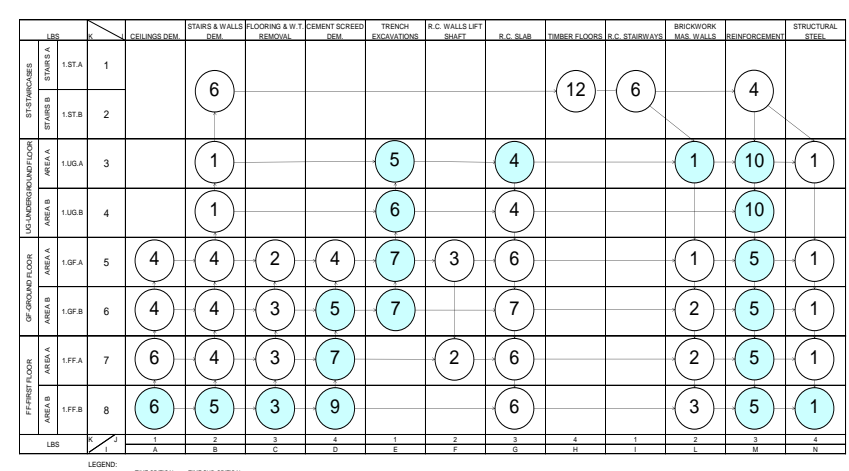

(Di) Di

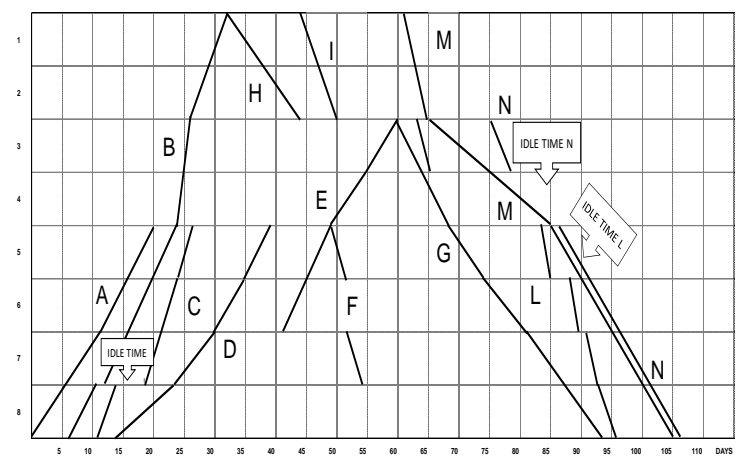

Fig. 2. (a) Sample project scheduling with REPNET, (b) Time -space chart of the REPNET sample project.

\subsection{Takt time planning with REPNET}

Takt time planning is method of work structuring that has the objective of setting a pace, known as Takt time, at which each trade can complete its work in each assigned work zone [7], [8]. The word "Takt" or "Taktzeit" in German means "beat", the regularity with which something happens or get done [6], [8]. In the Lean construction context Takt time is the unit of time within which a unit of production must be produced in order to match the rate at which that product is needed by the customer. Takt time is the supply rate needed to satisfy the customer, the demand rate. The idea of the Lean approach to takt planning and control is to bring the processes necessary for creating value into a uniform flow [6]. Takt planning can be carried in five iterative steps: 1 ) data gathering; 2 ) zone and takt definition; 3) trade sequence identification; 4) determination of individual trade durations; 5) workflow balancing; 6) production schedule finalization [7]. Takt time in construction can be identified with a top-down approach or a bottom-up approach. The top - down approach identifies the time frame within which the work has to be completed, assuming it set and known, and then the needed resources are loaded to activities. The bottom - up approach identifies the available resources and then identifies the maximum production capacity of the slowest trade and therefore identifies the takt time [8]. Resources of different trades can be balanced to improve the overall output in a feed-back check of production design alternatives. As uniformity and consistency between trades can never be achieved in practice, project processes need to be adjusted to a uniform project takt if possible. Takt is dependent on process variability, but is not constrained by this, and in practice a weekly takt is often selected for construction projects [6]. Takt time can be defined for a specific work-space or for an entire project. A space unit is where each trade performs its work in the planned sequence, therefore takt needs to be the same for each trade working in that space unit. Takt for one phase of construction to another one of the same project can be different, even from the takt of each space units. Theoretically it can be said that the most desirable phase or project takt should be the Least Common Multiple (LCM) of the takt times of the different production lines, i.e work-spaces. Due to construction project complexity, pertinent literature suggests a unique project takt time of one week [6]. Possible takt time can be easily understood in the REPNET resource - space chart, just identifying the highest duration of each trade in each workspace unit, i.e. each line of the chart. When the slowest activities of each workspace have been detected (see Fig. 3, green nodes), the possible takt times of each work units can be found (see table 2). Therefore, resource balance can be pursued to improve takt time planning in each space units. This means that resources can be added to the slowest activity to decrease takt time in a work-space unit, or a resources can be subtracted from faster activities to adapt them to the takt time and save resources. Anyway, this optimization process should take into account another lean workflow principle, the continuity of resource flow, i.e. the continuity of crew work in the REPNET columns.

\subsection{Sample application}

A case study of a building rehabilitation project has been used to test the proposed procedure. Only the demolition and structural reinforcement phases have been considered to keep constant the LBS (Fig. 2 (a) and (b), table1). The REPNET chart makes possible to detect easily takt times for each space-unit following the rule of the slowest trade in the space path (Fig. 3 (a), tab. 2). It should be observed that the work continuity requirement for each crew is already fulfilled for almost all trades, as displayed in the time - 
space chart. In fact, crews in activities B and C have very short interruptions of work, and only in activities $\mathrm{L}$ and $\mathrm{N}$ crews have some idle time (Fig. 2 (b)). All the remaining activities fulfill the work continuity requirement, meaning there are no waiting times in the workflow of crews. Therefore, the modification of the schedule in terms of balancing the duration of activities in the space units to fulfill takt time requirements should take into account the need of continuity of resource flows in the project. In the pilot study only activities B and I have been balanced in space path 1-2 as they were at the end of the resource path and they did not modify the project total duration (Fig 3 (b)).

Table 1. Sample Project activity list.

\begin{tabular}{|c|c|c|c|c|c|c|c|c|c|}
\hline \multirow[b]{2}{*}{ Id } & \multirow[b]{2}{*}{ Activtit description } & \multirow{2}{*}{$\begin{array}{c}\text { Duration } \\
\text { of repetitive } \\
\text { activity }\end{array}$} & \multicolumn{7}{|c|}{ Duration in space units } \\
\hline & & & $1-2$ & 3 & 4 & 5 & 6 & 7 & 8 \\
\hline$A$ & Ceilings demolition & 20 & & & & 4 & 4 & 6 & 6 \\
\hline $\mathrm{B}$ & Stairs \& walls demolition & 25 & 6 & 1 & 1 & 4 & 4 & 4 & 5 \\
\hline $\mathrm{C}$ & Flooring and wall tiles removal & 11 & & & & 2 & 3 & 3 & 3 \\
\hline $\mathrm{D}$ & Cement screed demolition & 25 & & & & 4 & 5 & 7 & 9 \\
\hline$E$ & Trench excavations & 25 & & 5 & 6 & 7 & 7 & & \\
\hline $\mathrm{F}$ & Reinforced concrete walls of lift shaft & 5 & & & & 3 & & 2 & \\
\hline G & Reinforced concrete slab & 33 & & 4 & 4 & 6 & 7 & 6 & 6 \\
\hline $\mathrm{H}$ & Timber floors & 12 & 12 & & & & & & \\
\hline 1 & Reinforced concrete stairways & 6 & 6 & & & & & & \\
\hline $\mathrm{L}$ & Brickwork masonry walls & 9 & & 1 & & 1 & 2 & 2 & 3 \\
\hline M & Reinforcement of brick masonry & 44 & 4 & 10 & 10 & 5 & 5 & 5 & 5 \\
\hline $\mathrm{N}$ & Structural steel & 5 & & 1 & & 1 & 1 & 1 & 1 \\
\hline
\end{tabular}

Table 2. LBS and Takt time detection.

\begin{tabular}{lcccc}
\hline Floor & Space unit & LBS code & LBS Id & Takt Time \\
\hline $1^{\wedge}$ F-First Floor 1.FF & area B & 1.FF.B & 8 & 9 \\
& area A & 1.FF.A & 7 & 7 \\
GF -Ground Floor 1.GF & area B & 1.GF:B & 6 & 7 \\
& area A & $1 . G F . A$ & 5 & 7 \\
UG - Underground Floor 1.UG & area B & 1.UG.B & 4 & 10 \\
& area A & 1.UG.A & 3 & 10 \\
ST - Staircases 1.ST & area A + B & 1.ST. & $1-2$ & 12 \\
\hline
\end{tabular}

\section{Conclusions}

Takt time is a Lean Construction approach to work structuring aimed at improving process performance by balancing the workflow. A process-oriented approach for construction scheduling can be used as a starting point to balance the workflow of resources through takt time planning and control. The REPENET heuristic displays project activities in each space unit of construction process with a Precedence Diagram plotted on a resource-space chart. Therefore, possible takt times of each space unit can be easily detected, but the work continuity requirement in each resource path should be taken into account for the optimization process. In fact, due to construction project complexity the two flow optimizations, takt time search in the space units and idle time elimination in the resource paths may need different work structuring choices. Future research work will be aimed at the optimization process of both workflows, of resources to avoid idle time of crews and of work through the sequence of activities and their takt times in each workspace of the project. 


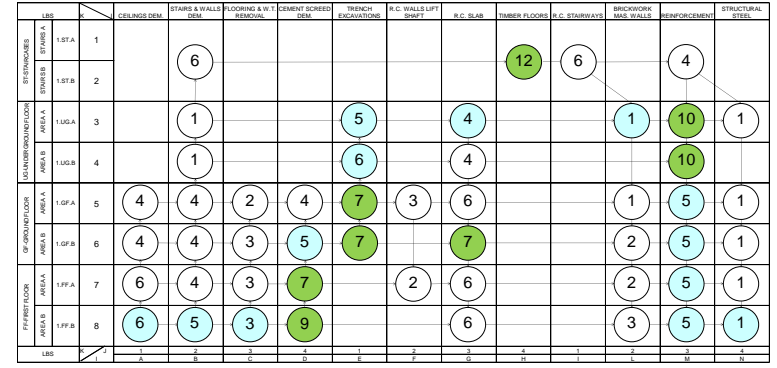

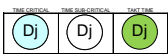

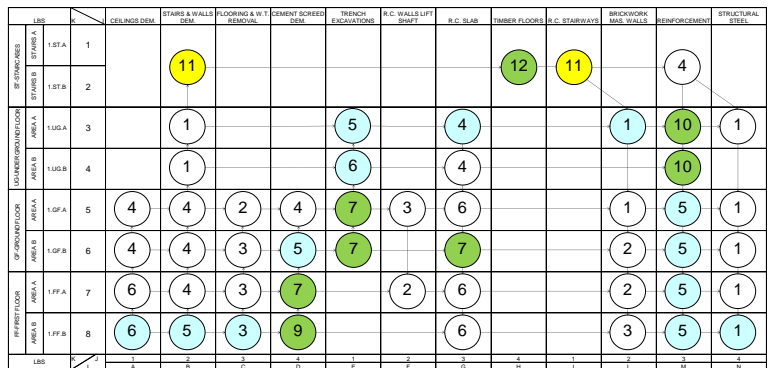

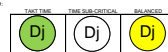

Figure 3: Pilot study: (a) Takt time detection (b) Balancing of activities.

\section{References}

[1] D.R. Riley, V.E. Sanvido, Patterns of Construction-Space Use in Multistory Buildings. Journal of Construction Engineering and Management vol. 121, No. 4, December, 1995.

[2] L. Koskela, Application of New Production Philosophy to Construction, CIFE Technical Report \#72, Stanford University, USA, September, 1992.

[3] L. Koskela, A. Tezel, V. Patel, 'Theory of Quality Management: Its Origins and History' In:, Proc. 27th Annual Conference of the International Group for Lean Construction (IGLC). Dublin, Ireland, 3-5 Jul 2019. pp 1381-1390 https://doi.org/10.24928/2019/0259

[4] G. Ballard, G. Howell. Shielding Production: Essential Step in Production Control, Journal of Construction Engineering and Management, ASCE Vol.124 No.11, 1998.

[5] H.G. Ballard, The Last Planner System of Production Control, Thesis for the degree of Doctor of Philosophy, School of Civil Engineering, University of Birmingham, 2000.

[6] M. Binninger, J. Dlouhy, S. Haghsheno, 'Technical Takt Planning and Takt Control in Construction.' In:, 25th Annual Conference of the International Group for Lean Construction. Heraklion, Greece, 9-12 Jul 2017. pp 605-612 https://doi.org/10.24928/2017/0297

[7] Frandson, K. Berghede, I.D. Tommelein, Takt Time Planning for Construction of Exterior Cladding. Proceeding of the 21st Annual Conference of the International Group for Lean Construction (IGLC), Fortaleza Brasil, pp 527-536, 2013.

[8] I.D. Tommelein, Collaborative Takt Time Planning of Non - Repetitive Work. Proceeding of the 25th Annual Conference of the International Group for Lean Construction (IGLC) LC302017 Vol. 2, pp 745-752, 2017. https://doi.org/10.24928/2017/0271

[9] Akinci, M. Fischer, R. Levitt, R. Carlson, Formalization and Automation of time-space conflict analysis, Journal of Computing in Civil Engineering, 16 (2) pages 124-134, 2002. https://doi.org/10.1061/(ASCE)0887-3801(2002)16:2(124)

[10] A. Ciribini, G. Galimberti, 4D Project Planning and H \& S Management, Proceedings of CIB W78's 22nd International Conference on Information Technology in Construction, Dresden, Germany, CIB publication 304, 2005.

[11] K. Kähkönen, Interactive Decision Support System for Building Construction Scheduling, Journal of Computing in Civil Engineering, 8(4), pp. 519-535, 1994.

[12] K. El Rayes, O. Moselhi, Resource-driven scheduling of repetitive activities Construction Management and Economics, 16, 433-446, 1998.

[13] K.J. Yi, H. Lee, Y.K. Choi, Network Creation and development for Repetitive-Unit Projects Journal of Construction Engineering and Management, 128(3), 257-264, 2002. https://doi.org/10.1061/(ASCE)0733-9364(2002)128:3(257)

[14] R. Kenley, O. Seppänen, Location-Based Management for Construction: planning, scheduling and control, Routledge, Spon Press, 2010, U.K.

[15] C.C.Y. Tsao, I.D. Tommelein, E.S. Swanlund, G.A. Howell, Work Structuring to achieve integrated Product-Process Design. Journal of Construction Engineering and Management, vol. 130, no. 6, pp. 780-789, 2004. https://doi.org/10.1061/0733-9364/2004/130:6

[16] N.P. Garcia-Lopez, M. Fischer, L.F. Alarcón, "Work structuring for flow" In: Proc. 27th Annual Conference of the International. Group for Lean Construction (IGLC), Pasquire C. and Hamzeh F.R. (ed.), Dublin, Ireland, pp. 311-322, 2019. https://doi.org/10.24928/2019/0140.

[17] M. Bragadin, K. Kähkönen. Resource - Space Charts for Construction Work Space Scheduling. Proceedings of the CIB World Building Congress Intelligent Built Environment for Life(vol. III), may 30 - june 3, 2016, Tampere, Finland. Tampere University of Technology. Report 18. pp. 677-688. ISBN 978-952-15-3743-1 